\title{
KENNIS EN VERWAGTINGE VAN DIE PRIMIGRAVIDA OOR BARING
}

\author{
M.B. Bester en A.G.W. Nolte
}

\section{OPSOMMNG}

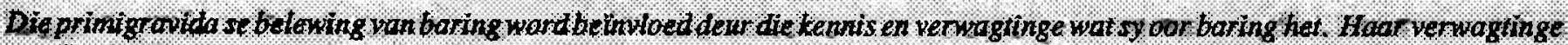
oor baring baseer sp op die intigitng wat sy by die voargeboorte-voorbereidingstlasse, die verpteagpersaneel, haor noedter,

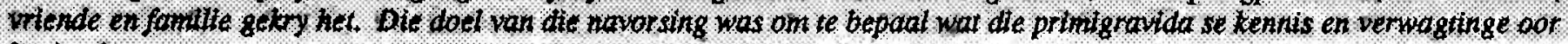
bowting h:

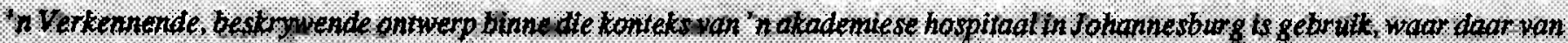

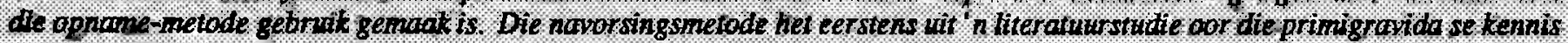

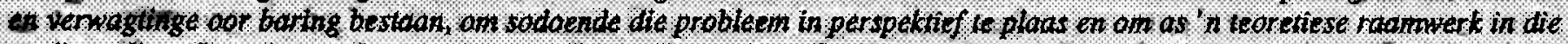

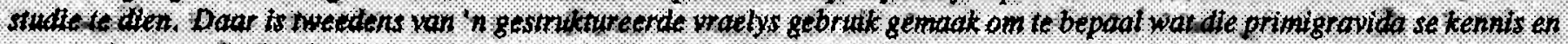
verwagtinge oor barting ts.

Uit die navorsing blylt dit dar die respondente ontaer rikende ternis oor baring en die hantering van pyn in baring het. Hierdie

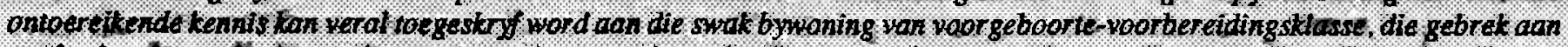

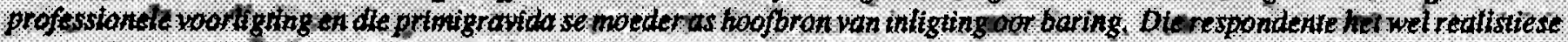

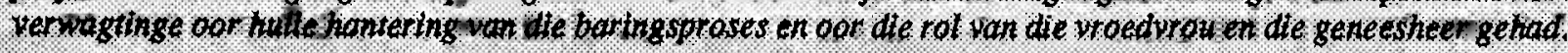

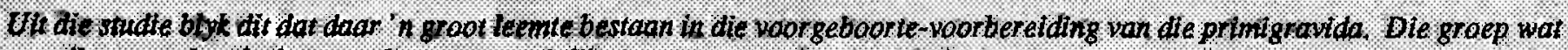
asn die nawarsing deetgeneem her, was gevolg tit nie genoeg voorbereiop die baringsproses on realistiese venwagtinge ie he nie.

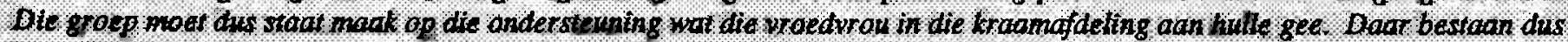

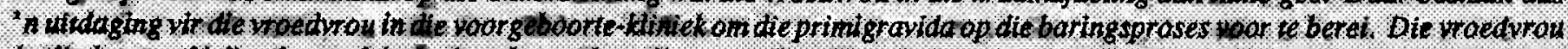

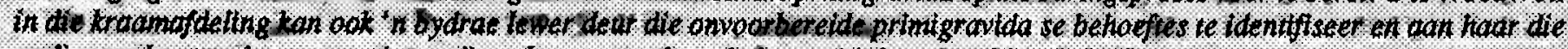

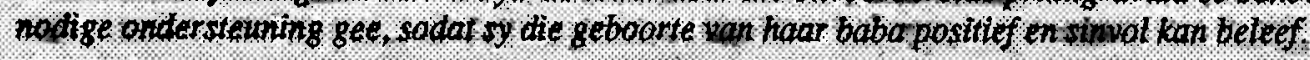

\section{SUMUARY}

The primigravida's experience of chilbbinth is influenced by the knowledge and expectations she has of childbinth. Hier axpectations of childbinth are based on the information she got from the antenatal clinic, the nutsing staff her mather, friends andfinmity. The purpose of thiv research was to deternine the knowledge ond expecturtous the printigravida has of childbirth.

An exploratory, descriptwe destgn was used with the context of on academic hospital hn lohanneburg. The survey method was used. The method of research fiestlyconsisted of a literature study of the primigravidat skiowiedge and expectations of childbirih. This was dons in order to put theproblen in perspective and also to serve as a theoreticat framework for the study. Secondly, a structured quetionnaire wass used ta matie a sumey of the primigrovido' sibnowledge and expections of chitdbirth.

Fram this researdh it is cledr that the responderts had insufficient knowledge of childabirh and the kanding of paln during

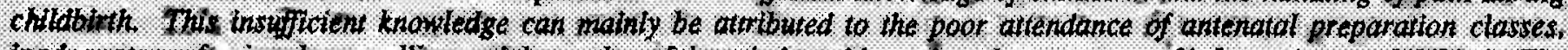
inadequate professional counseling and the mother of the primigravida as the primary source of information on childbirth. The respondients, however, had realistic expectationswith regard to their handing of labour, aswell as ofthe role of the midwifle and the docter.

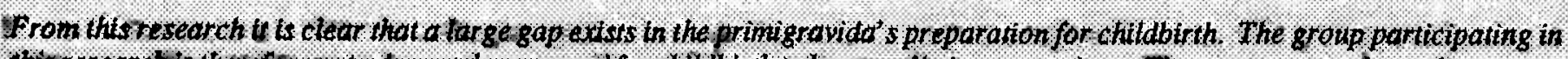

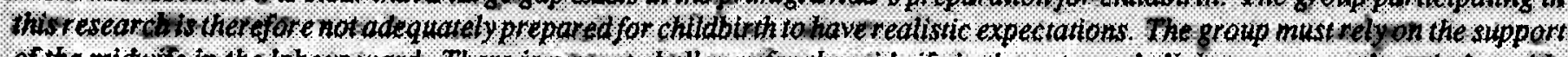
of the midwife in the labow ward. There is a great challengefor the nidwife in the antenatal clinic toprepare the primigrovida for childbirth. The midwife in the labaur ward can olso contribute by identifying the needs of the unprepared primigravida and supporfing her so that she experiences the birth of her baby as a positive and meaningful event.

\section{AGTERGROND VAN DIE PROBLEEM}

Die primigravida het sekere verwagtinge en vooropgestelde menings oor die geboorteproses en haar belewing daarvan. Die verwagtinge wat sy koester, het sy gevorm op grond van die kennis wat sy verkry het uit een of ander inligtingsbron, hetsy haar moeder, vriende, familie of die voorgeboorte-kliniek.

Die primigravida het hierdie verwagtinge veral ten opsigte van die verpleegpersoneel en haar geneesheer en ook die mate van ondersteuning wat sy gaan kry. Sy het ook sekere verwagtinge oor die voorkoms en gedrag van haar baba (Stolte, 1987:99).

Angs, spanning en die verlies van selfbeheersing is gevoelens wat algemeen voorkom wanneer die primigravida se 
verwagtinge nie ooreenstem met wat werklik gebeur nie (Roberts, 1983:64). Die onrealistiese verwagtinge veroorsaak dat sy haar baringsproses as negaticf ervaar. Haar selfbeeld is swak en sy beskou haarself as ' $n$ mislukking. Hierdie negatiewe gevoelens kom veral voor wanneer die primigravida, as gevolg van gebrekkige kennis, haarself op 'n normale bevalling voorberei en daar dan ' $n$ ingreep soos 'n keisersnee of 'n geassisteerde verlossing gedoen moet word (Beatty, Gutkowski, Moleti \& Yeransian-Nassery, 1985:325). Die meeste primigravidas wat hulle op ' $n$ normale bevalling voorberei, het wel 'n nominale ongekompliseerde baringsverloop. Primigravidas moet hulle egter daarop voorberei dat daar altyd 'n moontlikheid bestaan dat komplikasies kan ontstaan wat ' $n$ ingreep sal noodsaak.

Die primigravida se verwagtinge en kennis oor baring speel ' $n$ belangrike rol in haar belewing van ouerskap. Baie vrouens meet hulle vermoë om goeie ouers te wees aan hulle optrede en hantering van die geboorteproses. Indien hulle die baringsproses negatief beleef, kan hulle dalk ouerskap in 'n negatiewe lig beskou, en andersom. Die primigravida se belewing van die geboorteproses het ook 'n invloed op die moeder-kind-binding, afhangende daarvan of haar belewenis positief of negatief was (Mercer, 1985: 20 en 210).

Navorsing het ook getoon dat daar 'n verband tussen die moeder se angs en verlengde baring bestaan. Die moeder se angs veroorsaak 'n verhoging in die plasma-epinefrienvlak, wat 'n inhiberende uitwerking op die uterienwerking het, met gevolglike verlengde baring (Lederman, Lederman, Work \& McCann, 1979: 94; Simkin, 1986: 228; Levinson \& Shnider, 1979: 173). Grantley Dick-Read het in sy teorie oor natuurlike kindergeboorte genoem dat kennis oor baring die angs-spanning-pyn-kringloop verbreek (Mozingo, 1978: 47).

\section{PROBLEEMSTELLING}

Onvoldoende kennis en onrealistiese verwagtinge oor baring kan voorkom word indien die primigravida voldoende kennis oor baring het, wat realistiese verwagtinge skep en 'n positiewe geboorte-ervaring moontlik maak. Dit is dus belangrik om vas te stel wat die primigravida se verwagtinge is ten einde 'n volledige beraming te doen, voordat die nodige ondersteuning tydens baring aan haar verleen kan word.

\section{DEFINIËRING VAN TERME}

\section{Primigravida}

'n Primigravida word beskou as 'n vrou met haar eerste swangerskap.

\section{Baring}

Vir die doeleindes van hierdie studie verwys baring na die drie stadia van baring:

(a) Die eerste stadium wat bestaan uit die aanvang van baring totdat die serviks 10 cm ontsluit is. (b) Die tweede stadium duur vanaf die volle ontsluiting van die serviks totdat die baba gebore is.

(c) Die derde stadium duur vanaf die einde van die verlossing van die baba totdat die nageboorte volledig verlos is (Nolte, Slabber, Visser \& Brummer, 1987: 132).

\section{Ondersteuning}

Ondersteuning word gebied om:

- Die moeder se pyn te verlig,

- 'n veilige omgewing vir die moeder en baba te skep.

- die primigravida se houding en gedrag tydens baring te skep,

- die primigravida se houding en gedrag tydens baring te aanvaar en

- in haar behoeftes te voorsien.

Die ondersteuning versterk die primigravida se vermož om normaal te funksioneer (Anderson, 1979: 18).

\section{Verwagtinge}

Volgens die Verklarende Handwoordeboek van die Afrikaanse Taal (1981:1276) word "verwagting" beskyf as ' $n$ handeling van te verwag of te hoop. ' $n$ Verwagting kan beskou word as ' $n$ verstandelike vooruitskatting (persepsie) van hoe dit gaan voel wanneer 'n persoon haar in 'n spesifieke situasie bevind.

\section{NAVORSINGSONTWERP}

'n Verkennende, beskywende ontwerp binne die konteks van 'n akademiese hospitaal in Johannesburg word gebruik, waar daar van die opname-metode gebruik gemaak is.

\section{NAVORSINGSMETODE}

'n Literatuurstudie is gedoen ten opsigte van die kennis en verwagtinge van die primigravida oor baring en die invloed van onrealistiese verwagtinge cor die verloop van baring, om sodoende die probleem in perspektief te plass en om as 'n teoretiese raamwerk vir die studie te dien.

'n Gestruktureerde vraelys met die literatuurstudie is as konseptuele raamwerk gebruik om te bepaal wat die primigravida se kennis en verwagtinge oor baring is.

\section{STEEKPROEF}

Die steekproef sluit alle blanke primigravidas in wat gedurende 'n tydperk van 11 weke in 1989 die voorgeboorte-kliniek by 'n akademiese hospitaal in Johannesburg besoek het.

\section{Steekproefkriteria}

Daar is van nie-waarskynlikheidseleksie gebruik gemaak, waarby alle primigravidas wat aan die steekproefkriteria voldoen en die kliniek tydens 'n sekere periode besoek het, betrek is.

Die volgende steekproefkriteria is van toepassing:

- Primigravidas tussen die ouderdom van 15 en 29 jaar is gekies, omdat dit die mees algemene ouderdomme is waartydens swangerskappe voorkom.

- Slegs primigravidas met 'n swangerskapduur van 37 weke en meer is by die steekproef betrek. Dié periode is die aangewese tydperk, aangesien die primigravidas in die laaste weke van die derde trimester is en die aanvang van baring enige dag kan realiseer. Vanaf die sewe-en-dertigste week van 'n swangerskap behoort die primigravida reeds voorbereid te wees op die geboorte van die baba. Haar verwagtinge oor die baringsproses, die baba en ouerskap behoort reeds gevestig te wees. Die primigravida beskik gewoonlik dan reeds oor die nodige kennis om haar op die baringsproses voor te berei.

\section{DIE MEETINSTRUMENT}

'n Gestruktureerde vraelys is gebruik wat op die literatuurstudie gebaseer is. Die vraelys bestaan uit geslote sowel as oop-einde-vrae.

Die vraelys bestaan uit vier afdelings:

Afdeling A: 'n Opname word gemaak van die algemene inligting oor die primigravida, byvoorbeeld haar swangerskapduur, huwelikstaat en ouderdom.

Afdeling B: Dit bestaan uit 10 op-einde-vrae waar 'n opname gedoen word oor die pasiënt se verwagtinge oor baring.

Afdeling C: Bestaan uit vyf multi-responsvrae en 'n sesde vraag wat deur die primigravida beantwoord word wat vir 'n elektiewe keisersnee bespreek is. Die res van die vrae het dan nie op haar betrekking nie.

Afdeling D: Dit bestaan uit 10 vrae waar die primigravida "Ja", "Nee" of "Onseker" antwoord. Hierdie vrae bepaal hoofsaaklik haar kennis oor baring.

Die betroubaarheid van die meetinstrument

In die geval van die meetinstrument is dit egter nie moontlik om die betroubaarheid statisties te bepaal nie. Aangesien daar in die vraelys kennis en verwagtinge bepaal word, kan daar dus nie van 'n toets-hertoets-metode gebruik gemaak word nie, omdat die eerste toets die primigravida kan motiveer om die inligting te bekom.

Dle geldigheidsbepaling van die meetinstrument

Die meetinstrument is vir inhoud- en siggeldigheid ondersoek. 
Inhoudsgeldigheld

Die inhoudsgeldigheid van 'n meetinstrument word gewoonlik as voldoende beskou in die geldigheidsbepaling van die instrument (De Wet, Monteith, Venter \& Steyn, 1981:299). In hierdie geval is die inhoud $v$ an die vraelyste op die literatuurstudie gebaseer.

\section{Siggeldigheid}

Die siggeldigheid van 'n meetinstrument word bloot gebaseer op die waameming van die instrument om te bepaal of dit meet wat dit veronderstel is om te meet (Uys \& Basson, 1983:88). Die vraelys is deur twee kenners op die gebied van Verloskunde en die samestelling van meetinstrumente geëvalueer. Die instrument is opgestel om die kennis en verwagtinge van primigravida oor baring te meet. Volgens die kennis meet die instrument hierdie aspekte. Die instrument voldoen dus aan die vereistes van siggeldigheid.

\section{DIE UITVOER VAN DIE NAVORSING}

Die toestemming en goedkeuring van die pasiënt is verkry deur middel van 'n dekbrief wat die vraelys vergesel het.

Die navorsing is oor ' $n$ tydperk van 11 weke, vanaf Oktober tot November uitgevoer. Die primigravidas besoek die kliniek Maandae, Woensdae, Vrydae en soms Donderdae. Die dag voor kliniekbesoek word die persone wat vir die volgende dag se kliniek bespreek is, se lêers deurgegaan. Die primigravida wat aan die steekproefkriteria voldoen, $\mathbf{k y}$ 'n vraelys met 'n pen in haar lêer. Die volgende dag word die primigravida deur die kliniekpersoneel ingelig oor die belang $v$ an die studie en die invul van die vraelys. Die primigravida moet by die voorgeboortekliniek die dekbrief lees, die vraelys invul, dit in die koevert plaas en toeplak en aan die kliniekpersoneel terugbesorg. Die primigravida mag glad nie die vraelys huis toe neem nie, omdat sy tuis die nodige inligting kan bekom, en dit die geldigheid van die studie sal beinvloed. Die kliniekpersoneel is deur die navorser opgelei om die primigravida met die invul van die vraelys behulpsaam te wees.

Dit gebeur dikwels dat persone nie 'n bespreking vir die volgende kliniek doen nie, en dan net daar opdaag. Indien die primigravida aan die steekproefkriteria voldoen, is dasr aan haar 'n vraelys gegee om in te vul. Die ingevulde vraelyste is dan gereeld by die kliniek afgehaal. ' $n$ Lys van die primigravidas wat reeds die vraelys ingevul het, is by die kliniek gehou, om te verseker dat een persoon nie twee keer 'n vraelys invul nie.

\section{DIE RESULTATE VAN DIE NAVORSING}

Die steekproef het uit 29 blanke primigravidas bestaan. Hulle ouderdomme het tussen 15 en 29 jaar gewissel met 'n swangerskapduur van 37 weke en meer. Al 29 respondente het die gestruktureerde vraelys met hul besoek aan die kliniek ingevul.
Die resultate van die navorsing is deur middel $v$ an beskrywende statistiek en frekwensietabelle aangebied. Die resultate word afdeling vir afdeling aangebied.

\section{AFDELING A: ALGEMENE INLIGTING}

Onder algemene inligting word die biografiese besonderhede van die respondent weergegee. Die stadium van swangerskap van die grootste groep respondente $(41,4 \%)$ was 37 weke. Uit die groep was $48,3 \%$ van die respondente ongetroud en $41,4 \%$ getroud. Die grootste groep van die respondente, te wete $58,6 \%$ was tussen die ouderdom van 20-24 jaar en 34,5\% tussen 15-19 jaar. Wat opvoedkundige kwalifikasies betref, het $41,4 \%$ van die respondente standerd $8,34,5 \%$ standerd 10 en $6,9 \%$ standerd 10 én 'n diploma.

\section{AFDELING B: DIE RESPONDENT SE VERW AGTINGE OOR B ARING}

Die aanbieding $v$ an hierdie afdeling was in die vorm van oop-einde-vrae, sodat die respondent spontaan haar verwagtinge kon verwoord. Die verwagtinge wat die respondent genoem het, is deur die navorser geèvalueer en toe volgens realistiese en onrealistiese verwagtinge beoordeel.

Die respondente het realistiese verwagtinge oor hulself $(75,9 \%)$, die verpleegpersoneel (79,3\%) en die geneesheer gehad, maar 'n groot getal respondente $(72,4 \%)$ het onrealistiese verwagtinge oor die duur van baring gehad. 'n Groot groep $(86,6 \%$ ) het geen idee gehad wat die toelating tot die kraamafdeling behels nie, wat strydig is met die resultate van die hoë persentasie respondente $(79,3 \%)$ wat realistiese verwagtinge oor voorgeboorte-voorbereiding gehad het. Slegs $5,2 \%$ van die respondente het realistiese verwagtinge oor pyn gehad.

\section{AFDELING C: DIE RESPONDENT SE INLIGTINGSBRON OOR BARING}

In hierdie afdeling is daar 'n opname gemaak oor wie die respondent se grootste en naasgrootste bron van inligting is. Uit die opname blyk dit dat die moeders van die respondente hulle grootste, sowel as naasgrootste bron van inligting oor baring is. Naas die primigravida se moeder, is familielede en vriende ander belangrike bronne van inligting.

Daar is ook vasgestel oor watter onderwerpe die respondent die meeste en die minste inligting ontvang het. Die meeste inligting wat die respondente ingewin het, was oor borsvoeding, terwyl die minste inligting ingewin is oor die hantering van pyn tydens baring, en die belang van asemhaling tydens baring.

\section{AFDELING D: DIE RESPONDENT SE KENNIS OOR BARING}

Uit die resultate blyk dit dat $62,1 \%$ van die respondente geen kennis het oor die oorsaak van pyn in baring nie, terwyl $27,6 \%$ van die respondente onseker was oor die oorsaak van pyn tydens baring. Dit blyk verder dat $58,6 \%$ van die respondente geweet het dat wanneer die vliese skeur, dit nie beteken dat sy ' $n$ "drogeboorte" gaan hê nie. 'n Groot getal respondente $(72,4 \%)$ was onseker oor wat die term "pv" beteken. Uit die studie blyk dit dat die respondente weinig of geen kennis oor die toepassing van asemhalingsoefeninge tydens baring gehad het nie.

'n Groot getal respondente $(55,2 \%)$ was ook onseker oor die tekens van ware baring, terwyl $6,9 \%$ van die respondente geen kennis oor die tekens van ware baring gehad het nie. Meer as die helfte van die respondente $(55,2 \%)$ het geweet wat die funksie van die kardio-tokograaf is. Dit kan moontlik toegeskryf word aan die feit dat 'n kardio-tokograaf dikwels in die kliniek gebruik word om nie-stres-toetse op die pasiënte uit te voer.

\section{GEVOLGTREKKINGS}

\section{DIE HUWELIKSTAAT VAN DIE RESPONDENT}

Uit die opname blyk dit dat $48,3 \%$ van die respondente ongetroud is en dat $6,9 \%$ ongetroud is en saamwoon. Meer as die helfte van die steekproef bestaan dus uit ongehude moeders. Hierdie hoë persentasie kan toegeskryf word aan die feit dat die primigravidas van 'n tehuis vir ongehude moeders die spesifieke kliniek by die hospitaal besoek. Die hoë persentasie ongehude moeders kon moontlik ' $n$ invloed op die resultate gehad het.

\section{DEE RESPONDENT SE}

\section{VERWAGTINGE OOR BARING}

Die swak bywoning van voorgeboorte-voorbereidingsklasse $(72,4 \%)$ word weerspieël in die respondente se verwagtinge oor pyn in baring, die hantering daarvan, sowel as hulle verwagtinge oor die toelating tot die kraamafdeling.

Die respondente se verwagtinge ten opsigte van die ondersteuning van hul eggenoot is slegs $48,4 \%$. Die lae persentasie kan toegeskryf word aan die groot getal ongehude moeders wat by die steekproef ingesluit is.

Uit die navorsing kan daar tot die gevolgtrekking gekom word dat die bywoning van voorgeboorte-voorbereidingsklasse 'n belangrike rol speel in die primigravida se verwagtinge oor baring en al die fasette wat daarmee gepaard gaan.

\section{DIE RESPONDENT SE BRON VAN INLIGTING OOR BARING}

Uit die navorsing blyk dit dat die respondent se moeder, haar vriende en familie 'n groot rol speel in die verskaffing van inligting oor baring. Die ontoereikende oordra van inligting deur die mediese personeel word weerspießëBl in die onvoldoende kennis wat die respondente oor baring het. 'n Ander moontlikheid is dat die respondent nie die 
mediese personeel met die verskaffing van die inligting vertrou nie en dat sy haar om hierdie rede na bekende bronne soos haar moeder, vriende en familie wend.

Die respondent het die meeste inligting oor borsvoeding. wat ' $n$ natuurlike proses is, ingewin. Dit verklaar ook waarom die respondent se hoofbron van inligting haar moeder is. Die respondent het die minste inligting oor die hantering van pyn en die toepassing $v$ an asemhalingsoefeninge gedurende baring ontvang. Dit kan toegeskryf word aan die ontoereikende verskaffing van inligting deur professionele persone en die $s$ wak bywoning van voorgeboortevoorbereidingsklasse.

\section{DIE RESPONDENTE SE KENNIS OOR BARING}

Die basiese kennis van die respondente is vasgestel. Die navorser het uit ondervinding in die praktyk geleer dat dit juis die basiese kennis oor baring is wat in die respondent van belang is. Verskeie primigravidas, en selfs multigravidas het teenoor die navorser opgemerk dat hulle baie pyn tydens baring ervaar het, aangesien "die ysbene nie wou oopmaak nie". By die ruptuur van membrane glo baie pasiënte dat wanneer die vliese skeur en die vrugwater minder word, hulle ' $n$ "drogeboorte" gaan hê wat pynliker gaan wees. Hierdie wanopvattings kan toegeskryf word aan die inligting $w$ at hulle moeders, vriende en familie verskaf en die gebrek aan voorligting deur professionele persone. Aan die respondente is gevra of 'n "pv" 'n vaginale ondersoek is. 'n Groot persentasie $(\mathbf{7 2 , 4 \%}$ ) van die respondente was nie seker wat die term beteken nie. Dit is belangrik dat sy weet wat die afkorting beteken, aangesien dit dikwels gebeur dat die vroedvrou of die geneesheer 'n afkorting gebruik wanneer hulle met of voor haar praat. Dit kan hasr baie frustreer indien sy nie weet wat vir of oor haar gesê word nie.

Uit die navorsing kan daar tot die gevolgtrekking gekom word dat die respondente se ontoereikende kennis en onrealistiese verwagtinge oor baring toegeskryf $k$ an word aan die swak bywoning van voorgeboorte-voorbereidingsklasse en die gebrek aan professionele inligting.

\section{AANBEVELINGS}

\section{AANBEVELINGS TEN OPSIGTE VAN DIE PRAKTYK}

Alhoewel die navorsing slegs by een voorgeboorte-kliniek uitgevoer is, is dit van waarde in dié sin dat dit terselfdertyd 'n evaluering was van die diens wat by die betrokke kliniek gelewer word. Daar word a anbeveel dat die voorligting an primigravidas verbeter word. Dit is ook noodsaaklik dat daar 'n beter vertrouensverhouding tussen die primigravida en die mediese personeel bewerkstellig word, sodat die primigravida haar eerder tot professionele voorligting wend as om van haar moeder, vriende en familie as primêre bron van inligting gebruik te maak. Daar moet ook 'n daadwerklike poging aangewend word om die primigravida op te voed en te motiveer om die belang en waarde van voorgeboorte-voorbereidingsklasse te besef en dit by te woon.

'n Groot deel van die steekproef het uit ongehude moeders bestaan. Dit op sigself kan sosiale en psigiese probleme meebring. Die voorligting aan en ondersteuning van die primigravida moet van s 6 ' $n$ aard wees dat dit die groep met hulle unieke probleme akkommodeer.

Die aanbevelings in die praktyk is dus om voorkomende maatreëls in te stel wat verbeterde voorgeboorte-voorbereiding en professionele voorligting insluit. Kuratiewe maatreèls wat in die geval van die afwesigheid van bogenoemde toegepas word, wat in ondersteuningsprogram aan die primigravida deur die vroedvrou insluit, moet ook ingestel word.

\section{OPLEIDING}

Dit is belangrik dat die verpleegpersoneel die nodige opleiding ontvang, sodat hulle 'n raming kan maak van die primigravida se kennis en verwagtinge oor baring en hulle daarvolgens voorligting aan haar kan gee. Die vroedvrou moet ook vir die primigravida se individuele behoeftes voorsiening maak deur middel van die toepassing $v a n$ ' $n$ ondersteuningsprogram aan die individu wat nie voorberei is vir baring nie.

\section{VERDERE NAVORSING}

Verdere navorsing kan gedoen word waarin die belang van ondersteuning deur die vroedvrou, die pasiënt se eggenoot, of enige ander persoon van belang, ondersoek word.

Aangesien 'n groot getal respondente 'n lae opvoedkundige kwalifikasie (st.8) het, kan daar verdere navorsing gedoen word om die verband tussen die primigravida se opvoedingspeil en die invloed daarvan op haar kennis en verwagtinge oor baring te bepaal.

\section{SAMEVATTING}

Dit blyk uit die navorsing dat voorgeboortevoorbereidingsklasse en voorligting deur professionele persone 'n groot rol speel in die kennis en verwagtinge wat die primigravida oor baring het. Daar le dus vir die vroedvrou en die geneesheer 'n groot opvoedingstaak voor om die primigravida te oortuig om voorgeboorte- voorbereidingsklasse by te woon. Vir die vroedvrou in die voorgeboorte-kliniek is die uitdaging om die primigravida wat nie die voorgeboortevoorbereidingsklasse bywoon nie, deur middel van voorligtingspraatjies te bereik.

Dit is noodsaaklik om te alle tye ' $n$ raming en evaluering van die primigravida se kennis en verwagtinge oor baring te doen om te verseker dat sy toereikende kennis het en sodoende realistiese verwagtinge oor baring het, ten einde een van die belangrikste gebeurtenisse in haar lewe positief en sinvol te beleef.

\section{VER WYSINGS}

ANDERSON, G 1979. Operational definition of "support". Journal of Obstetric, Gynaecologic and Neonatal Nursing, 5(1), Jan-Feb 1979: 17-18.

BEATTY, J; GUTKOWSKI, MV: MOLETI. CM \& YERANSIAN-NASSERY, L 1985. Anger generated by unmet expectations. American Journal of Maternal Child Nuring, 10(5), Sept-Oct 1985: 324-327.

DE WET, JJ; MONTEITH, JL de K; VENTER, PA \& STEYN, HS 1981. Navorsingsmetodes in die opvoedkunde. Durban-Pretoria: Butterworth.

LEDERMAN, RP; LEDERMAN, E; WORK, BA \& MCCANN, DS 1979. Relationship of psychological factors in pregnancy to progress in labour. Nursing Research, 28(2), Mar-Apr 1979: 94-97.

LEVINSON, C \& SHNIDER, SM 1979. Catecholomines and the effects of maternal fear and its treatment on uterine function and circulation. Birth and the Family Journal, 6(3), Fall 1979: 167-174.

MERCER, RT 1985. Relationship to the birth experience to later mothering behaviour. Journal of Nurse-Midwifery, 30(4), July-Aug 1985: 204-211.

MOZINGO, JN 1978. Pain in labour: a conceptual model for intervention. Journal of Obstetric, Gynaecologic and Neonatal Nursing, 7(4), Jul-Aug 1978: 47-49.

NOLTE, AGW; SLABBER, CF; VISSER, AA \& BRUMMER, WE 1987. Verloskunde vir verpleegkundiges. Pretoria en Kaapstad Academica.

ODENDAAL, FF; SCHOONEES, PC; SWANEPOEL, CJ; DU TOIT, SJ \& BOOYSEN, CM 1981. Verklarende Handwoordeboek van die Afrikaanse Taal. Tweede uitgawe. Johannesburg en Kaapstad: Perskor.

ROBERTS, JE 1983. Factor influencing distress from pain during labour. Maternal-Child Nursing Journal, 8(1), Jan-Feb 1983: 62-66.

SIMKIN, $P$ 1986. Stress, pain and catecholamines in labour. Part 1 A review. Birth, 13(4), Dec 1986: 227-233.

\begin{tabular}{c} 
MB Besier \\
M.Cur (Verlostundige en Neonatale \\
Verpleegkunde) RAU \\
Dasent: Verloskunde, \\
Ann Latsky Verpleegkollege \\
AGW Nolte \\
DLiut. et Phil. Verpl) UNISA \\
Professor in Verpleegkunde, RAU \\
\hline
\end{tabular}

